\title{
Climate change and demand of emergency care in Japan
}

\author{
Kei Nagai ${ }^{1,2}$ \\ ${ }^{1}$ Department of Nephrology, Hitachi General Hospital, Japan \\ ${ }^{2}$ University of Tsukuba Hospital Hitachi Social Cooperation Education Research Center, Japan
}

\begin{abstract}
Both the frequency and severity of heat stress-related health problems have been increasing globally, probably due to global warming. The Intergovernmental Panel on Climate Change published a landmark climate report, the 6th Assessment Report, which shocked the world. It emphasized that anthropogenic activities, such as the combustion of fossil fuels, oil, gas, and coal, were responsible for climate change. The combination of population aging, and increased temperatures has meant that the number of people requiring emergency transport for heatstroke has been increasing in Japan from 2008 to 2020 . The increase in ambient temperatures and the number of patients requiring emergency transport were strongly correlated (Spearman correlation coefficient: $r=0.669$ and $P=0.008$ ). Like many human activities, medical care is resource intensive and contributes significantly to climate change through the consumption of energy and water, as well as the emission of greenhouse gases. As healthcare professionals, we need to be cognizant of how our eco-friendly activities both on and off the job can contribute to saving both the patients and us.
\end{abstract}

Key words: heat stroke, climate change, emergency care

(J Rural Med 2022; 17(1): 57-58)

\section{To the Editor}

Although most people are concerned about the catastrophic consequences of climate change on vulnerable regions, climate change is a global issue. Both the frequency and severity of heat stress-related health problems have been increasing globally, due to global warming ${ }^{1)}$. On August 9, 2021, the United Nations Intergovernmental Panel on Climate Change published a landmark climate report, the 6th Assessment Report (AR6), which shocked the world ${ }^{2}$. In uncharacteristically direct terms, the report emphatically stated that anthropogenic activities, such as the combustion of fossil fuels, oil, gas, and coal, were responsible for climate change. In recent years, Japanese people have ex-

Received: August 25, 2021

Accepted: September 22, 2021

Correspondence: Kei Nagai, Department of Nephrology, Hitachi General Hospital, 2-1-1 Jonan-cho, Hitachi, Ibaraki 317-0077, Japan E-mail:knagai@md.tsukuba.ac.jp

This is an open-access article distributed under the terms of the Creative Commons Attribution Non-Commercial No Derivatives (by-nc-nd) License $<\mathrm{http}: / /$ creativecommons.org/ licenses/by-nc-nd/4.0/>. perienced extreme weather events, such as heatwaves and floods, at frequencies that are unexpectedly high ${ }^{3)}$. Faced with this new reality, people need to develop solutions to mitigate various social and economic problems related to climate change. In addition, people need to change the way they think about climate change and how to moderate their activities to minimize damage to the environment. Although the burden on our healthcare system may also be affected by local and global changes in ambient temperatures, clinical evidence linking climate change to human health is still rarely described in Japan ${ }^{1,4)}$.

Heat stress triggers heatstroke, which can lead to confusion, weakness, and other symptoms, including organ injuries ${ }^{1)}$. Using temperatures in Tokyo as a proxy for ambient temperatures in Japan, temperatures have been rising in recent years (Figure $1 \mathrm{~A})^{5}$. As a result, the incidence of heatstroke has increased, particularly among the elderly, who often have a reduced ability to maintain body fluid volume and electrolyte homeostasis. Consequently, the combination of population aging, and increased temperatures has meant that the number of people requiring emergency transport for heatstroke has been increasing in Japan (Figure 1B $)^{6}$. The increase in ambient temperatures and the number of heatstroke patients requiring emergency 
A
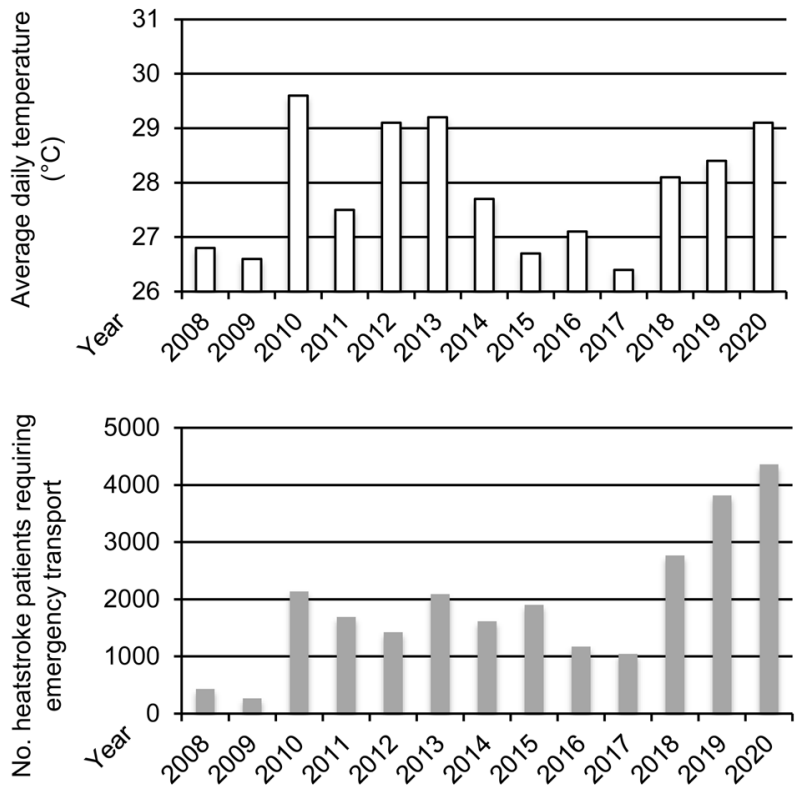

C

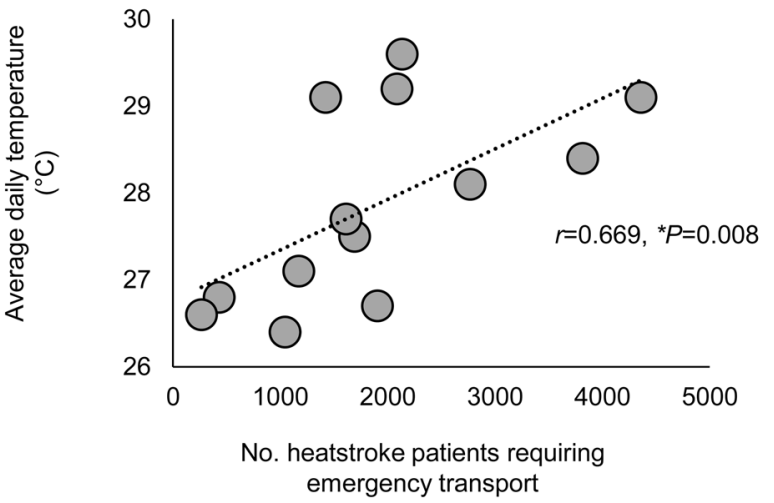

Figure 1 Summer temperatures and heatstroke requiring emergency care in Japan.

A) Mean August temperatures in Tokyo, Japan from 2008 to $2020^{5}$. B) Number of heatstroke patients transported by ambulance in August in Tokyo ${ }^{6}$, referenced with permission. C) Correlation between average temperature and number of ambulance transports (Spearman correlation coefficient: $r=0.669$ and $P=0.008$ ). transport were strongly correlated (Spearman correlation coefficient: $r=0.669$ and $P=0.008$ ) (Figure 1C). While there are miscellaneous confounding factors that affect this relationship, this result convinced us of the increase in the seriousness of heat-stress-related health problems in Japan over the last decade. The highest temperature ever recorded in Japan occurred in 2021, and it seems that the number of patients requiring emergency care for heatstroke will also increase this year.

I hope that AR6 will ratchet up the pressure on world leaders to move away from fossil fuels and reduce the emissions that cause global warming. Environmental problems are often difficult for healthcare providers to understand. However, like many human activities, medical care is resource intensive and contributes significantly to climate change through the consumption of energy and water, and the emission of greenhouse gasses ${ }^{7}$. As healthcare professionals, we need to be cognizant of how our eco-friendly activities both on and off the job can contribute to mitigate increases in global warming and limit the burden that an increase in the number of cases will place on emergency care. For Japan, this environmental mitigation policy will lead to an improvement in the health of residents and a reduction in the risk of the collapse of the healthcare system.

\section{Acknowledgment}

The author was supported in part by JSPS grant No. 18KK0431 and the Japanese Association of Dialysis Physicians grant No. 2019-1 for the preparation of this article.

\section{References}

1. Watts N, Adger WN, Ayeb-Karlsson S, et al. The Lancet Countdown: tracking progress on health and climate change. Lancet 2017; 389: 1151-1164. [Medline] [CrossRef]

2. The Intergovernmental Panel on Climate Change (IPCC) Climate Change 2021: The Physical Science Basis. Contribution of Working Group I to the Sixth Assessment Report of the Intergovernmental Panel on Climate Change. In: Masson-Delmotte V, Zhai P, Pirani A, Connors SL, Péan C, Berger S, Caud N, Chen Y, Goldfarb L, Gomis MI, Huang M, Leitzell K, Lonnoy E, Matthews JBR, Maycock TK, Waterfield T, Yelekçi O, Yu R, Zhou B, eds. Cambridge University Press, Cambridge, 2021; In press.

3. Wang SSY, Kim H, Coumou D, et al. Consecutive extreme flooding and heat wave in Japan: Are they becoming a norm? Atmos Sci Lett 2019; 20 : e933. [CrossRef]

4. Nagai K, Barraclough K, Ueda A, et al. Sustainability in dialysis therapy: Japanese local and global challenge. Ren Replace Ther 2021; 7: 42. [CrossRef]

5. Japan Meteorological Agency. Past weather data. 2021 https://www.data.jma.go.jp/obd/stats/etrn/index.php. (Accessed Aug. 8, 2021)

6. Fire and Disaster Management Agency. Heat stroke information in Japan. 2021 https://www.fdma.go.jp/disaster/heatstroke/post3.html.(Accessed Aug. 8, 2021)

7. Nagai K, Suzuki H, Ueda A, et al. Assessment of environmental sustainability in renal healthcare. J Rural Med 2021; 16: 132-138. [Medline] [CrossRef] 